\section{Factors associated with HIV/AIDS sexual risk among young women aged 15-24 years in Nigeria}

\author{
Chinekwu A. Obidoa, Cyr E. M'Lan, \\ Stephen L. Schensul
}

Department of Community Medicine and Health Care, University of Connecticut, USA

\section{Abstract}

The growing rate of sexual risk-taking among young people contributes significantly to the spread of the HIV/AIDS epidemic in Nigeria. This study, explores the influence of socio-demographic, HIV/AIDS awareness and female empowerment on the sexual risk behaviors of unmarried Nigerian women aged 15-24. The data presented in this paper was drawn from the 2003 Nigeria National Demographic and Health Survey. The sample consisted of unmarried women aged 15-24 in the dataset. Data was collected through a structured and interviewer administered questionnaire. Multivariate logistic regression models were used to identify the most important predictors of sexual risk behaviors. Sexual risk-taking is relatively high among unmarried young women. Among those who are sexually active, $80 \%$ indicated that they did not use a condom during their first sexual encounter. Regression analysis revealed that younger age, lower HIV/AIDS prevention and transmission knowledge, lower knowledge of where to obtain condoms, lower material standard of living and greater intimate partner violence were significantly associated with sexual risk-taking in this population. Findings revealed that the sexual behavior of unmarried Nigerian women aged 15-24 is influenced by a complex matrix of factors. Identifying specific processes and contexts that promote the concentration of risk among sub-sections of young unmarried women aged 15-24 years in Nigeria should be a research and intervention priority.

\section{Introduction}

Sub-Saharan Africa remains the region hardest hit by the worldwide HIV/AIDS pandemic with the highest rates in Southeastern and Southern Africa. West Africa generally has lesser prevalence rates. Nonetheless, Nigeria, the most populous country in Africa, has the second highest number (2.9 million) of people living with HIV/AIDS in Africa. ${ }^{1}$ Young people aged 15-29 are the most affected by the
HIV/AIDS epidemic in Nigeria. ${ }^{2}$ HIV/AIDS rates in this population grew almost steadily within the last decade. In 2003, estimates from the national sentinel survey showed a prevalence rate of 5.0\% among young people aged 15-24 years (FMOH, 2004-2005). ${ }^{3,4}$ The prevalence rate of the infection among young people fell to $4.1 \%$ in 2005 . In 2008 , the prevalence rate was slightly lower at $4.0 \%$. Similar to the epidemics in other countries in sub-Saharan Africa, the Nigerian HIV/AIDS epidemic affects young women disproportionately. Data from the United Nations Joint Program on HIV/AIDS (UNAIDS) shows that out of 2,600,000 adults aged 15 and above living with HIV/AIDS in Nigeria, more than half $1,600,000(62 \%)$ of them were women. ${ }^{1}$

Sexual risk-taking has been identified as a major factor contributing to the spread of the epidemic among youth in Nigeria. ${ }^{5}$ Data from both national and local surveys consistently indicate that unprotected sex among young people in Nigeria remains high despite the prominent threat of the HIV/AIDS infection. ${ }^{6,7}$ Sexual risk-taking among adolescents in Nigeria involves early age at first sexual intercourse, inconsistent or nonexistent condom use, sex with multiple sexual partners and transactional sex..$^{5-8}$ The 2003 National Health and Demographic Survey (NDHS) conducted in Nigeria ${ }^{7}$ showed that $22 \%$ and $17.4 \%$ of the never married young women and men respectively aged $15-19$ years had sex within the last 12 months, yet only $23 \%$ of the women and $32.8 \%$ of the men used a condom during their last sexual encounter and $4.9 \%$ of the men within the same age range reported having two or more sexual partners. ${ }^{7}$ These sexual risk behaviors expose young people to many negative health outcomes such as HIV and other sexually transmitted diseases, teenage pregnancy, and early marriage, and the numerous outcomes associated with these problems.

In response to the rise in HIV/AIDS infection rates among young people in sub-Saharan Africa, public health research attention has been directed to the factors associated with the sexual behavior of young people in this region. A general consensus from the findings is that youth sexual risk is determined by a complex matrix of factors, which include individual, relational, family-based, structural and cultural-based factors. ${ }^{9-14}$ Some of the socio-demographic factors that have been linked to youth sexual risk include: younger age, low educational status, rural place of residence, and lower socio-economic status. ${ }^{15-17}$ Research on the influence of HIV/AIDS knowledge and perception of risk on youth sexual risk-taking show that young people who have lower HIV/AIDS knowledge, lower perception of HIV/AIDS risk and negative attitudes about contraceptives are more likely to engage in
Correspondence: Chinekwu A. Obidoa, The Institute for Community Research 2 Hartford Square West, Suite 100, 146 Wyllys Street, Hartford, CT 06106-5128, USA.

Tel. +1.860.278.2044 (Ext.303) Fax: +1.860.278.2141 E-mail: chinekwuobidoa@yahoo.co.uk

Key words: HIV/AIDS, young women, sexual risk, Nigeria.

Contributions: the authors contributed equally and substantially to this study.

Conflict of interest: the authors report no conflicts of interest.

Received for publication: 10 December 2010.

Revision received: 17 January 2011.

Accepted for publication: 3 January 2012.

This work is licensed under a Creative Commons Attribution NonCommercial 3.0 License (CC BYNC 3.0).

(C) Copyright C.A. Obidoa et al., 2012

Licensee PAGEPress, Italy

Journal of Public Health in Africa 2012; 3:e15

doi:10.4081/jphia.2012.e15

sexual risk behaviors. ${ }^{17-20}$

While existing studies have been helpful in identifying the subgroups of youth having risky sex, there has been insufficient examination of factors, which would lend themselves to intervention and change. Several behavioral change theories such as the Theory of Planned Behavior $^{21}$ and the Social Cognitive Theory ${ }^{22}$ posit that behavior is a product of the interaction between several factors such as: knowledge, attitudes and perceived behavioral skills - social and psychological.

Behavioral skills, which can also be referred to as empowerment skills, enable people to clarify issues, make decisions, communicate effectively, make assertive efforts regarding a desired goal and develop interpersonal skills. ${ }^{23}$ There is evidence that these skills enable young people to translate information about HIV/AIDS into protective behaviors. ${ }^{24}$ In view of increasing evidence that despite relative high HIV/AIDS awareness and knowledge many young people continue to engage in high risk behaviors, ${ }^{7}$ investigation into the role of other factors such as behavioral skills and youth empowerment and their interaction with socio-demographic and knowledge-based factors is considered necessary.

The objectives of this study are i) to describe the pattern of sexual risk taking among young women aged 15 -24 years and ii) to examine factors associated with sexual risk behaviors in this population.

\section{Conceptual framework}

The conceptual model in this study proposes 
that sexual-risk taking among young unmarried Nigerian women is influenced by a broad range of factors, which include: socio-demographic factors, HIV/AIDS related factors and empowerment factors. Socio-demographic factors include indices such as: age, educational attainment, religion, residence type and socioeconomic status. HIV/AIDS related variables include: HIV/AIDS prevention and transmission knowledge, knowing someone who has died of AIDS, exposure to HIV/AIDS information, and attitudes towards HIV/AIDS information. Empowerment factors in this study refer to social and behavioral skills at that are important for engaging in safer sexual behavior. They include knowing where to obtain a male and female condom, discussing family planning methods with friends and perception of intimate partner violence. This last variable was added because research in other countries has shown that intimate partner violence is a predictor of sexual risk behaviors among women. Gender power imbalance permeates pre-marital sexual relationships. ${ }^{25}$ However, very few studies have explored how power and gender role ideologies operate in adolescent sexual relationships. ${ }^{26}$ This study assumes that young women who disclose greater disapproval of intimate partner violence may be more empowered to make positive sexual health choices. It is hoped that by including these indicators of behavioral and social skills a better understanding of the factors that influence sexual risk-taking in young Nigerian women will be elicited.

\section{Materials and Methods}

This study used data collected from the 2003 National Demographic and Health Survey carried out in Nigeria in 2003. ${ }^{7}$ The National Demographic and Health Survey is one of the most comprehensive Nigerian datasets that contains extensive information on the reproductive health of women between 15-49 years, and therefore provides a unique opportunity to study the antecedents of sexual behaviors of young women in the country. By using a nationally representative sample a better understanding of the factors that are associated with the sexual risk-behaviors of the most affected group by the HIV/AIDS epidemic in Nigeria can be obtained. Findings from this study provide more comprehensive information about the social epidemiology of the HIV epidemic in Nigeria, which can be used to inform prevention and intervention efforts.

The 2003 Nigerian NDHS survey sample was made up of 7225 households.

More than $90 \%$ of the 7985 eligible women were interviewed. All the women between ages 15-49 who were either residents or visitors in the households the night prior to the interview were eligible to be interviewed. ${ }^{7}$

The data set was obtained upon request by the researcher from the ORC Macro office based in Washington DC. Data for single women aged 15-24 years were identified and selected from the data set. Variables relevant to the study were identified and selected. A total of 1836 women aged 15-24 who had never been married were selected from the dataset. More than half $(1240 ; 67.5 \%)$ were $15-19$ years of age while $596(32.5 \%)$ were 20 years or older.

\section{Results}

Data analyses were carried out using a three-step process involving: examination of frequency distributions for both the dependent and independent variables. Bivariate analysis to assess associations between variables were examined using the Chi square test or the Fisher's test. Binary logistic regression was employed to examine the combined effect of the independent variables on the dependent variables. To avoid problems associated with using cross-sectional data to explain retrospective events, the associations between age at first sex and independent variables were examined in a different format. Due to the fact that age at first sex varied considerably across the sample, (ranging from less than ten years or more for some of the participants) it was considered methodologically inappropriate to explain associations between this event (first sex) and current socio-demographic, HIV/AIDS awareness and empowerment indices for all the participants. This potential problem was addressed by identifying participants who indicated they had sex for the first time at their current age. A total number of 51 participants who indicated their current age the same as their age at first sex was identified. This sample was grouped into two categories: age at first sex less or equal to 20 years and age at first sex above 20 years. Because of the small sample size, logistic regression was not performed, however, bivariate analyses were conducted to examine the association between younger age at first sex and older age at first sex and independent variables. Binary logistic regression was performed to examine the relationship between the dependent variables: recent sex and condom use at last sex and the independent variables. A sexual risk scale made up of both recent sex and condom use at last sex was created. Binary logistic regression was also preformed to examine the relationship between this sexual risk scale and independent variables. All analyses were performed using SAS vs 9.2 and were adjusted for the sampling weight. The survey logistic proce- dure was employed instead of the standard logistic procedure. The survey logistic procedure takes into account the sampling structure by making use of the cluster, strata, domain, sampling weight, and design effect used in the survey. Logistic regression models were used to select the most important predictors in each domain for each dependent variable. Independent variables that were significantly associated with the dependent variable from each domain were selected and included in a cumulative model that included all significant independent variables. This allowed the examination of the effects of independent variables on the dependent variable at the domain level as well as across domains. This procedure was repeated for each of the dependent variables and for the sexual risk scale. Odds ratios (ORs) and 95\% confidence intervals were computed for each variable in the logistic models.

\section{Study population description}

The mean age of the sample is 18.3 . Nearly three quarters (74.2\%) of the study population are not employed. The majority (66.6\%) of the women have secondary school education, (6.9\%), have no education, (19.5\%) have primary education, and (7.0\%) have higher education. Breakdown of the major ethnic groups are as follows: Igbo (28.8\%), Yoruba (19.4\%) and Hausa (6.8\%). About half (46.9\%) of the study population resides in urban areas, while $53.1 \%$ live in rural areas. About $84 \%$ of the participants have knowledge of four of the eight ways HIV/AIDS can be avoided. Less than half (40.2\%) of the population knows someone who has or has died of AIDS. A total of 59.1\% think that wife beating is justified in at least one circumstance. A high proportion $68.7 \%$ of the respondents indicated they did not know where to get a male condom. Only $3.6 \%$ indicated they knew where to get a female condom.

\section{Pattern of sexual risk behaviors \\ Age at first sex}

Out of 1836 unmarried women aged 15-24, $630(34.4 \%)$ reported they had had sexual intercourse. Table 1 identifies the frequencies of the sexual behaviors. The mean age for sexual debut is 16.7. The youngest age at first sexual debut was seven years. Age at first sex gradually increased arithmetically up to age fifteen and then declined at ages 16 and 17 . This decline however precedes a peak at age eighteen. Figure 1 shows the distribution of age at first sex in the population.

\section{Condom use and recent sexual activity}

A high proportion (80.5\%) of those who have had sexual intercourse did not use a condom during their first sexual debut and less than half $(22.7 \%)$ used condoms during their 
last sexual intercourse. The majority (80.3\%) of the women reported that their most recent sex was less than a year ago.

\section{Sexual risk scale}

The scale was created by aggregating the number of sexual risk behaviors reported by each woman. The scale ranged from 0-3. Based on the breakdown it can be interpreted that virtually all the women participate in high risk sexual activity.

\section{Factors associated with age at first sex}

Bivariate analyses ( $\chi^{2}$ test and Fishers test) were used to examine the association between independent variables and age at first sex. Results show that almost all (42 out of 51) the women who indicated they had sex for the first time the same year the survey was administered were below 20 years old $(\mathrm{P}=<0.0001)$. Age at first sex was only significantly associated with three other variables: employment, condom use at first sex and HIV/AIDS transmission knowledge. Women who were not employed were more likely to have had sex at a younger age. Women who had high HIV/AIDS transmission knowledge were more likely to have had sex after age 20, however this association was barely significant. Women who had sex before age 20 were more likely to have used a condom during their first sexual encounter than those who had sex after age 20 .

\section{Logistic regression \\ Recent sex}

In model I only age was significantly associated with recent sex. Odds ratios indicate that younger women (15-19 years) were 1.7 times more likely to have had sex less than a year prior to the survey. In model II no variable was found to be significantly associated with recent sex. Knowing where to obtain a male condom was the only variable significantly associated with recent sex in model III. Women who did not know where to obtain male condoms were 0.5 (half of the time) more likely to have had sex less than a year prior to the study. The final model included these two variables; both were found to be significantly associated with recent sex. Knowing where to obtain a male condom however had the strongest significance. Odds ratios are presented in Table 2.

\section{Condom use at last sex}

In model I material standard of living and condom use at first sex were significantly associated with condom use at last sex. The corresponding odds ratio indicates that young women who come from poorer households are half of the time (0.05) less likely to use a condom compared to those from richer house-

\section{Age at First Sex}

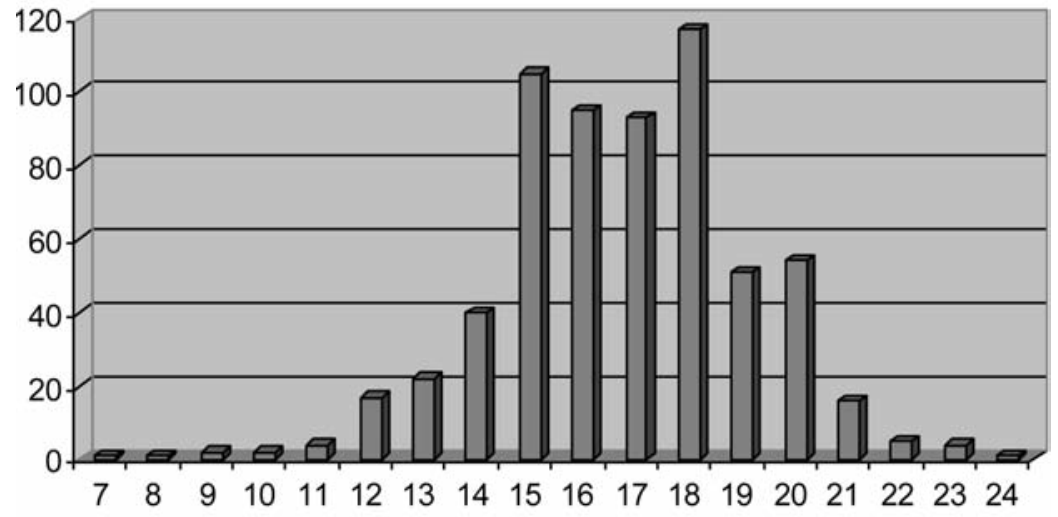

Figure 1. Age at first sex.

Table 1. Sexual risk behaviors.

\begin{tabular}{lcc} 
Variable & Total & $(\%)$ \\
Have had sexual intercourse & 630 & 34.7 \\
$\quad$ Have not had sexual intercourse & 1202 & 65.5 \\
Age at first sexual intercourse & 550 & 87.0 \\
$\quad<20$ years & 80 & 12.7 \\
$\quad>20$ years & & \\
Recent sex & 100 & 15.8 \\
$\quad$ Days ago & 126 & 19.9 \\
Weeks ago & 282 & 44.6 \\
Months ago & 121 & 19.1 \\
A year/years ago & & \\
Condom use at first sexual intercourse & 507 & 80.5 \\
$\quad$ No & 120 & 19.0 \\
Yes & & \\
Condom use at last intercourse & 364 & 57.8 \\
$\quad$ No & 143 & 22.7 \\
Yes & & \\
Sexual risk scale & 2 & 0.3 \\
Low risk & 2 & 0.3 \\
Some risk (2) & 123 & 19.5 \\
High risk (3) & 505 & 79.9 \\
\hline Very high risk (4)
\end{tabular}

Table 2. Odds ratios for logistic regression; recent sex.

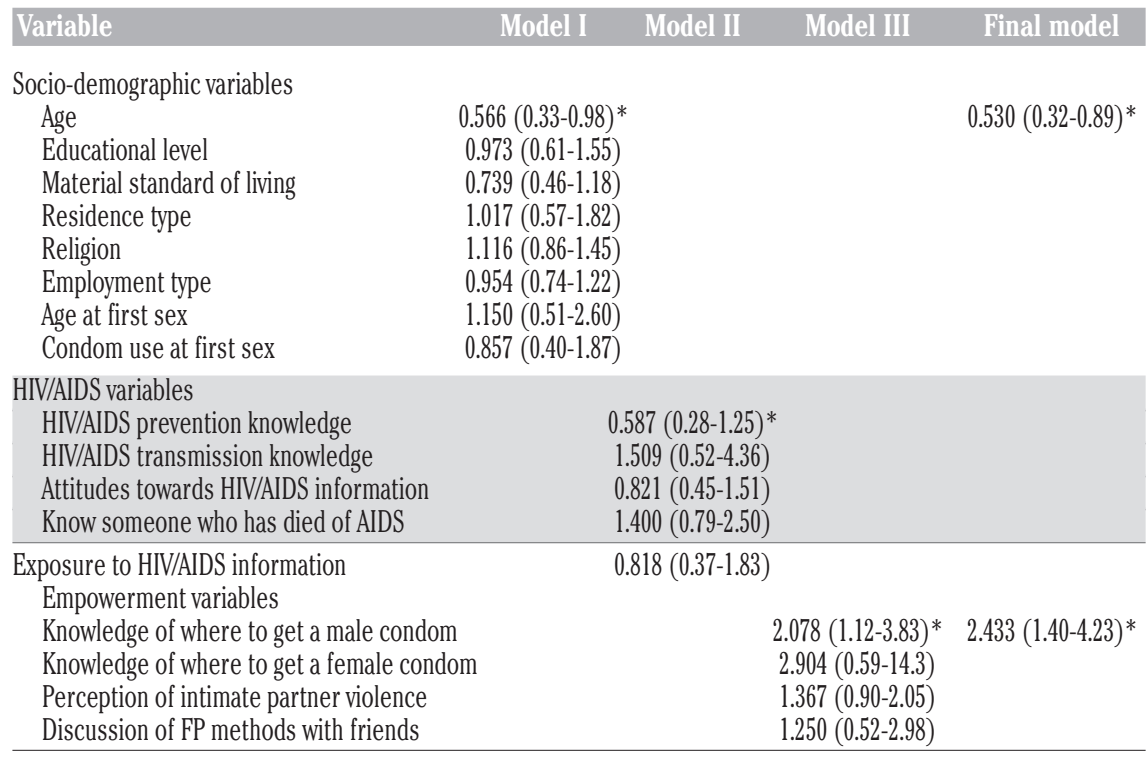

FP, family planning; ${ }^{*} \mathrm{P}=<0.05$ age 0 vs. 1 , male condom 0 vs. 1 . 
holds. Women who were older were also half of the time (0.05) times more likely to have used a condom during their last sexual encounter. In model II only HIV/AIDS transmission knowledge was significantly associated with condom use at last sex. Women who knew more ways HIV/AIDS can be transmitted were 0.4 times more likely to have used a condom during their last sexual encounter. In model III knowing where to get a male condom and perception of intimate partner violence were significantly associated with condom use at last sex. Women who knew where to obtain a male condom were two times more likely to have used a condom during their last sex. Women who did not approve of intimate partner violence were 1.5 times more likely to have used a condom in during their last sexual encounter. In the final model, material standard of living, condom use at first sex and knowledge of where to obtain a male condom were significantly associated with condom use at last sex. Odds ratios are presented in Table 3.

\section{Recent sex and condom use at last sex}

A sexual risk scale was created by merging recent sex and condom use at last sex. In model I, only age at first sex was significantly associated with sexual risk. Women who were older were less likely to engage in risk behavior (recent sex and no condom use at last sex). No variables were significant in model II. In model III only knowledge of where to get a male condom was significant with the dependent variable. Women who knew were to obtain condoms were half of the time (0.51) more likely to have engaged in sexual risk behavior. In the cumulative model, age and knowledge of where to obtain condoms were significant with recent sex and condom use at last sex. Odds ratios are presented in Table 4.

\section{Discussion}

The two objectives of this study were i) to describe the pattern of sexual risk taking and ii) to examine the influence of socio-demographic, HIV/AIDS related knowledge and empowerment factors on the sexual behavior of young women aged 15-24 year in Nigeria. Results from univariate analysis revealed that about a third (34.4\%) of the females sampled had had sex. Within this group, sexual risktaking is relatively high with over $80 \%$ indicating that they did not use a condom during their first sexual encounter. Almost all (94\%) of the women reported at least three or more sexual risk behaviors. A large (87.0\%) proportion of the women had sex before they were 20 years old. Regression analysis revealed that women who are younger in age, have low HIV/AIDS prevention and transmission knowledge, do not know where to obtain condoms, belong to the lower socio-economic sector and approve of intimate partner violence in at least one circumstance are more likely to engage in sexual risk behavior despite the relatively low odds ratios. These findings are similar to those of previous research among youth in countries in sub-Saharan Africa. $8,15,27$ They provide evidence that the factors that influence sexual risk-taking among young women are both individually and contextually based. Results from analyses revealed that there is a concentration of risk among young women who are sexually active. Of particular concern is the fact that

many of them become sexually active at a very young age. Age at first sex was not significantly associated with most of the independent variables examined in this study. Given the risk associated with younger age at first sex identifying the factors that shape sexual debut among young women is necessary for targeting of prevention programs.

Research on HIV/AIDS related awareness among youth in Nigeria indicates that young people have relatively high HIV/AIDS awareness. Although young people are aware of the HIV/AIDS disease, they lack comprehensive knowledge about specific ways on how HIV/AIDS is transmitted or can be prevented.

Results from this study also show that

Table 3. Odds ratios for logistic regression; condom use at last sex.

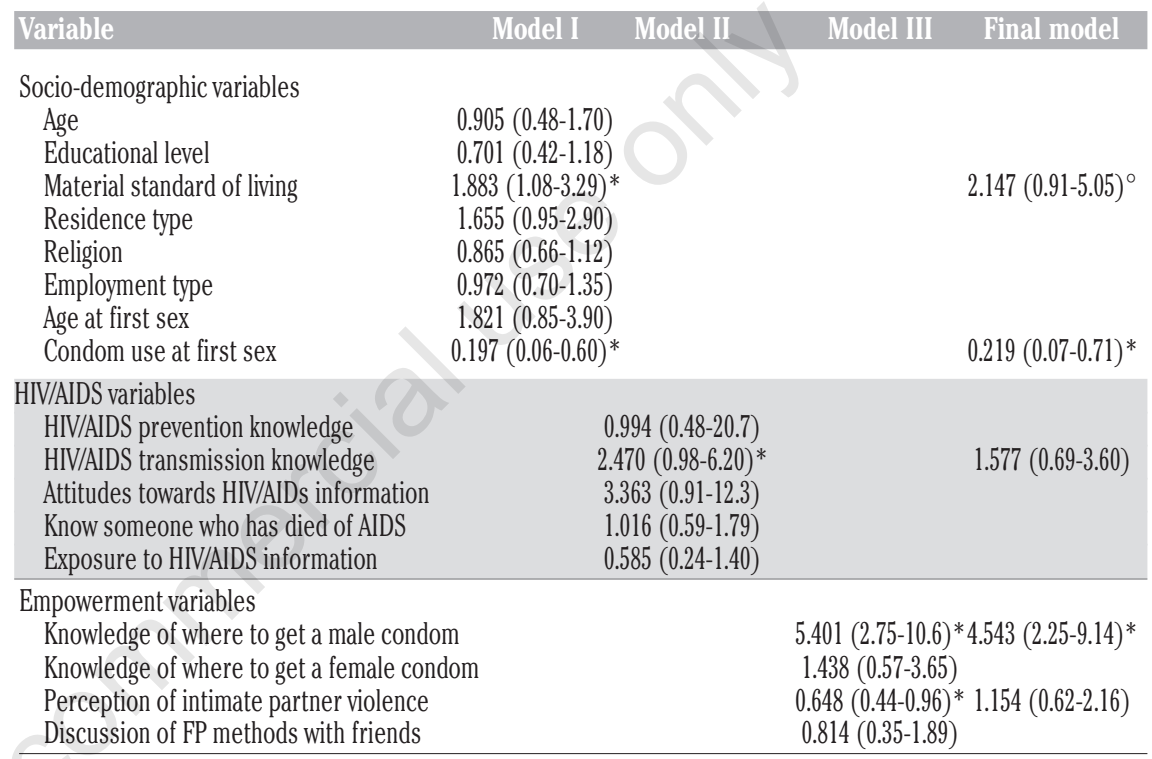

$\mathrm{FP}$, family planning; ${ }^{*} \mathrm{P}=<0.05 ;{ }^{\circ} \mathrm{P}=<0.01$

Table 4. Recent sex and condom use.

Variable Model I Model II Model III Final model

Socio-demographic variables Age

Educational level

Material standard of living

Residence type

Religion

Employment type

Age at first sex

Condom use at first sex

$0.506(0.27-0.94)^{*}$

$1.042(0.66-1.66)$

$0.741(0.47-1.18)$

$1.016(0.58-1.79)$

$1.098(0.84-1.42)$

$0.943(0.73-1.21)$

$1.495(0.80-2.78)$

$0.830(0.36-1.90)$

HIV/AIDS variables

HIV/AIDS prevention knowledge

HIV/AIDS transmission knowledge

Attitudes towards HIV/AIDS

Know someone who has died of AIDS

Exposure to HIV/AIDS information

$0.607(0.29-1.28)$

$1.655(0.59-4.61)$

$0.799(0.43-1.47)$

$1.444(0.81-2.57)$

$0.850(0.37-1.87)$

Empowerment variables

Knowledge of where to get a male condom

Knowledge of where to get a female condom

Perception of intimate partner violence

Discussion of FP methods with friends

$1.959(1.08-3.60)^{*} 0.561(0.33-0.94) *$

$3.000(0.60-14.85)$

$1.32(0.88-1.98)$

$1.291(0.54-3.07)$

FP, family planning; $* \mathrm{P}=<0.05$ 
women who are in the lower sector of the socio-economic ladder were more likely to engage in sexual risk behavior. Some of the factors that account for the strong association between low SES or poverty and higher likelihood of engaging in sexual risk include: limited knowledge about HIV/AIDS transmission and prevention, limited access to information and prevention materials as well as vulnerability to transactional sex. Unemployment and economic disenfranchisement in Nigeria have caused some young women to engage in marginal, often-menial occupations that expose them to opportunities to exchange sex for money or gifts. ${ }^{28-30}$ Some young women decide to be involved in sex work as a means to supplement their wages or provide for their needs. ${ }^{28}$ Some who do not get involved in sex work engage in other forms of sex transactions in which sex is exchanged for financial or material gifts. This exchange is usually with a male sex partner who is much older. In such relationships young women lack the psychological and social empowerment to insist on safer sex practices. Consequently, many are exposed to the risks of contracting HIV/AIDS and other STDs.

Based on the findings in this study, the subset of women at highest risk of contracting HIV/AIDS through risky sex appear to be those who are between 15-19 years who have limited HIV/AIDS prevention and transmission knowledge, and are in the lowest sector of the socioeconomic ladder. They are also the ones who lack empowerment skills to engage in safer sexual behaviors. Identifying specific processes and context that promote the concentration of risk among this sub-set of young unmarried women aged 15-19 years in Nigeria should be a research priority.

There are several limitations to this study. First this study was unable to explore the influence of a broad range of indicators for sexual behavior, socio-environmental, socio-cultural factors because indicators measuring those factors were not in the NDHS data set and because of inconsistencies in the data set in the form of missing data. Secondly, because of its cross-sectional nature, this study was affected by recall bias and measurement bias. As a result it was difficult to determine causality and temporal ordering of variables measured.

\section{Recommendations for HIV/AIDS pre- vention and intervention}

Findings from this study have several implications for HIV/AIDS prevention and intervention in Nigeria. Some of the major implications are i) HIV/AIDS education targeted to youth should be more comprehensive in nature. Such education should include specific information on how HIV/AIDS is transmitted and prevented. HIV/AIDS-related education should also include information on where young people can obtain accurate reproductive health information. ii) HIV/AIDS intervention programming should increasingly be expanded beyond education and information to include skill building programs for young people. Such programs should focus on building individual empowerment and interpersonal skills that are necessary for negotiating safer sexual behaviors.

\section{Conclusions}

This study provides valuable information about the determinants of sexual risk taking in young unmarried women aged 15-24 in Nigeria. Findings from this study affirm those made by other researchers about the sociodemographic and structural antecedents of the sexual behavior of young people. Since Nigeria has the highest number of young people aged 10-24 in sub-Saharan Africa, timely and appropriate implementation of these research-based suggestions in Nigeria assist with curbing the spread of the HIV/AIDS epidemic not only in Nigeria but also in a large proportion of the youth population sub-Saharan Africa.

\section{References}

1. United Nations Joint Program on HIV/AIDS (UNAIDS). Nigeria: epidemiological fact sheet on AIDS and sexually transmitted infections. Geneva: UNAIDS; 2006.

2. Onwuliri VA, Jolayemi OM. Reaching vulnerable and high-risk groups in Nigeria. In: Adeyi 0, Kanki, PJ, Odutolu 0, Idoko, editors. AIDS in Nigeria: A nation on the threshold. Cambridge: Harvard Center for Population and Development Studies; 2006. pp. 309-322.

3. Federal Ministry of Health Abuja, Nigeria. A technical report on the 2001 national HIV/Syphilis sentinel survey among pregnant women attending ante-natal clinics in Nigeria. Abuja: NASCAP; 2004.

4. Federal Ministry of Health Abuja, Nigeria. A technical report on the 2001national HIV/Syphilis sentinel survey among pregnant women attending ante-natal clinics in Nigeria. Abuja: NASCAP; 2005.

5. Bankole A, Singh S, Woog V, Wulf. Risk and protection: youth and HIV/AIDS in subSaharan Africa. New York: Alan Guttmacher Institute; 2004.

6. Dare 00, Oladepo 0, Cleland JG, Badru OB. Reproductive health needs of young persons in markets and motor parks in South West Nigeria. Afr J Med Sci
2001;30:199-205.

7. National Population Commission, Nigeria (NPC) \& ORC Macro. Nigeria Demographic and Health Survey 2003. Calverton, MD: National Population Commission \& ORC Macro; 2004.

8. Sunmola AM, Dipeolu M, Babalola S, Out AD. Reproductive, sexual and contraceptive behavior of adolescents in Niger State, Nigeria. Afr J Reprod Health 2004;6:82-92.

9. Gupta N, Mahy M. Sexual initiation among adolescent girls and boys: trends and differentials in sub-Saharan Africa. Arch Sex Behav 2003;32:41-53.

10. Mensch BS, Grant MJ, Blanc AK. The changing context of sexual initiation in sub-Saharan Africa. Population Council Working Papers; 2005. No. 206.

11. Oyefara JL. Family background, sexual behavior, and HIV/AIDS vulnerability of female street hawkers in Lagos metropolis, Nigeria. Int Soc Sci J 2005;57:687-98.

12. Kabiru CW, Orpinas P. Factors associated with sexual activity among high school students in Nairobi, Kenya. J Adolesc 2008;1-17.

13. Karim AM, Magnani RJ, Morgan GT, Bond KC. Reproductive and protective factors among unmarried youth in Ghana. Int Fam Plan Perspect 2003;29:14-24.

14. Kiragu K, Zabin LS. The correlates of premarital sexual activity among school-age adolescents in Kenya. Int Fam Plan Perspect 1993;19:92-7.

15. Meekers D, Klein M, Foyet L. Patterns of HIV risk behavior and condom use among youth in Yaounde and Douala, Cameroon. AIDS Behav 2003;7:413-20.

16. Gage AJ, Meekers D. Sexual activity before marriage in sub-Saharan Africa. Soc Biol 1994;41:22-60.

17. Kiragu K, Zabin LS. Contraceptive use among high school students in Kenya. Int Fam Plan Perspect 1995;21:108-13.

18. Adih WK, Alexander DS. Determinants of condom use to prevent HIV infection among Youth in Ghana. J Adolesc Health 1999;24:63-72.

19. Twa-Twa JM. The role of the environment in the sexual activity of school students in Tororo and Pallisa districts of Uganda. Health Transit Rev 1997;7 Suppl:67-81.

20. Eke AN. Socializing influences on HIV/AIDS-related risk behaviors among adolescents in Nigeria. Maryland: The Johns Hopkins University; 1997.

21. Ajzen I, Fishbein M. The influence of attitudes on behavior. In: Abarracin D, Johnson BT, Zanna MP, editors. The handbook of attitudes. Mahwah, NJ: Erlbaum; 2005. pp.173-221.

22. Bandura A. Self-efficacy: the exercise of control. New York: W. H. Freeman; 1997.

23. Moya C. Life skills approach to improving 
youth's sexual and reproductive heath. Washington DC: Advocates for Youth; 2002.

24. Tiendrebeogo G, Meijer S, Engleberg G, Africa Consultants International. Life skills and HIV education curricula in Africa: methods and evaluations. SD Publication Series: Office of Sustainable Development, Bureau of Africa. 2003; Technical Paper No. 119.

25. Odutolu 0, Adedimeji A, Odutolu 0, et al. Economic empowerment and reproductive behavior of young women in Osun state, Nigeria. Afr J Reprod Health 2003;7:92100.

26. Gage AJ. Female empowerment and adolescent demographic behavior. In: Presser HB, Sen G, editors. Women's empowerment and demographic processes: Moving beyond Cairo. Oxford Press: New York; 2000.

27. Glover EK, Bannerman A, Pence BW. Sexual health experiences of adolescents in three Ghanaian towns. Int Fam Plan
Perspect 2003;29:32-40.

28. Blum RW, Nelson-Mmari K. The health of young people in a global context. J Adolesc Health 2004;35:402-18.

29. Bamgbose 0. Teenage prostitution and the future of the female adolescent in Nigeria. Int $\mathrm{J}$ Offender Ther Comp Criminol 2002;46:569-85.

30. Ajuwon AJ, Shokunbi W. Women and the risk of HIV infection in Nigeria. Int $\mathrm{Q}$ Community Health Educ 1997;10:107-20. 